Article

\title{
Power Hardware in-the-Loop Testing to Analyze Fault Behavior of Smart Inverters in Distribution Networks
}

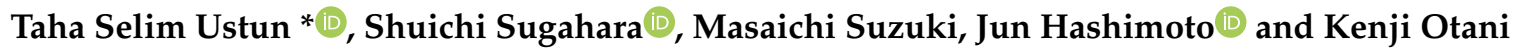 \\ Fukushima Renewable Energy Institute, AIST (FREA), National Institute of Advanced Industrial Science and \\ Technology (AIST), Koriyama 963-0298, Japan; shuichi.sugahara@aist.go.jp (S.S.); \\ suzuki-masaichi@aist.go.jp (M.S.); j.hashimoto@aist.go.jp (J.H.); k.otani@aist.go.jp (K.O.) \\ * Correspondence: selim.ustun@aist.go.jp
}

Received: 28 October 2020; Accepted: 10 November 2020; Published: 11 November 2020

\begin{abstract}
Deep penetration of distributed generators have created several stability and operation issues for power systems. In order to address these, inverters with advanced capabilities such as frequency and reactive power support the grid. Known also as Smart Inverters (SIs), these devices are highly dynamic and contribute to the power flow in the system. Notwithstanding their benefits, such dynamic devices are new to distribution networks. Power system operators are very reluctant toward such changes as they may cause unknown issues. In order to alleviate these concerns and facilitate SIs integration to the grid, behavior studies are required. To that end, this paper presents a power hardware-in-the-loop test set up and tests that are performed to study fault behavior of SIs connected to distribution networks. The details of the software model, SI integration with the real-time simulator, test results, and their analyses are presented. This experience shows that it is not trivial to connect such novel devices with simulation environments. Adjustments are required on both software and hardware fronts on a case-by-case basis. The encountered integration issues and their solutions are presented herein. The fault behavior of the SI with respect to the fault location is documented. It is observed that for faults that are close to SIs, momentary cessation of generation is observed. This needs to be tackled by device manufacturers as this phenomenon is very detrimental to health of a power system under fault conditions. Extensive PHIL test results show that several factors affect the fault behavior of an SI: fault location and its duration, SI mode of operation as well as extra devices housed in the casing. These results and their in-depth analyses are presented for a thorough understanding of SI behavior under fault conditions.
\end{abstract}

Keywords: grid integration studies; lab testing set up; grid simulators; fault behavior; distribution network fault studies

\section{Introduction}

Without a doubt, Renewable Energy (RE) is the most popular source of energy for the future [1,2]. New solutions are constantly developed to increase RE-based generation at all levels of power system operation [3-5]. This shift towards clean energy addresses contemporary issues such as global warming and sustainability [6,7]. However, traditional power systems are not designed to accommodate dynamic generation devices at all levels, especially at the distribution level [8,9]. Proliferation of RE-based Distributed Generators (DGs) causes unprecedented issues related to voltage and frequency stability as well as control and protection [10,11].

One very prominent issue is keeping frequency and voltage within acceptable margins [12]. Early generation inverters that were used for RE-based DGs did not provide any support mechanisms. They would inject real power into the system and disconnect if there is a voltage or frequency event. More often than not, this would add fuel to the fire. For instance, when a voltage drop occurs due 
to loss of generation, power output of these DGs would be needed for the system to help stabilize. For this reason, new generation inverters, i.e., Smart Inverters (SIs), are required to stay connected to the system [13]. With their advanced capabilities, they provide voltage and frequency support to help stabilize the system $[14,15]$.

Widespread use of SIs heavily relies on thorough study of their behavior under different system conditions. There are works that report SIs behavior under different operation conditions [16] as well as cyber-attacks $[17,18]$. However, there is no work that studies their behavior under fault conditions. Furthermore, works cited above use simulations based on mathematical models developed for SI. Since their fault behavior is not very well known, developing a simulation model for such transients is not an easy task. Therefore, power hardware-in-the-loop (PHIL) testing approach needs to be utilized. Recently, the PHIL testing approach has become popular [19-21]. However, the number of works that focus on fault behavior of distributed generators is very limited. The work in [22] only tests fault ride through behavior of a wind system. It does not solely focus on fault behavior of the wind system; fault occurs somewhere in the grid, not close to the generator and, most importantly, the tests are performed at transmission level. There is a clear need in the literature for a PHIL test setup that can be used to investigate fault behavior of renewable energy-based generators.

To address this knowledge gap, this paper presents a PHIL test setup and fault behavior tests results of a SI that has a large market-share in Hawaii and Japan [23]. The hardware wiring details, connection with the digital real-time simulator (DRTS) and power amplifier are presented. Furthermore, the simulated power system and fault conditions are also given. Hardware configuration as well as software modeling proved to be non-trivial and several challenges have been encountered. These challenges and their solutions are also documented for the benefit of researchers working in the field. Fault location is swept between two different conditions representing a fault at the terminals of the SI and a fault that is very far away in the grid. Furthermore, several tests with different fault durations are performed. Based on the tests results, the impact of fault location and duration is analyzed. All of these aspects are beneficial to researchers working in this field.

The major contributions of this work are as follows:

(a) A novel lab-test setup is developed to study the fault behavior of SIs. Details of wiring and PHIL configuration are presented.

(b) A simulation model is developed to specifically allow for fault behavior studies. Encountered modeling challenges as well as their solutions are reported. Researchers working in this field can benefit from these and design different test environments.

(c) Based on the result analyses, the fault behavior of SIs is documented. This behavior is correlated to the location and duration of the fault in the system. This is especially important as these devices are novel and very dynamic. Understanding their behavior is key to their widespread deployment which, in turn, facilitates renewable energy penetration.

(d) Grid codes and manufacturer notes are analyzed to further investigate fault behavior.

The rest of the paper is organized as follows: Section 3 presents the developed fault behavior study setup. Both hardware configurations and software models are documented in detail. Section 4 shows and analyzes obtained tests results. Different factors impacting the fault behavior are analyzed and discussed in detail. These include voltage and frequency deviations, SI modes, and overall system architecture inside the casing. Section 5 draws the conclusions and gives future work insights.

\section{Impact of Inverter-Interfaced DGs on Power System Operation}

Traditionally, distribution networks are designed for single-direction power flow for consumption. The addition of DGs, mostly RE-based, changes this paradigm completely [24]. Their integration into the system causes bi-lateral power flow and generation occurs near consumption. All these concepts are alien to power system protection assumptions that require a passive distribution network where the current flows from the Point of Common Coupling (PCC) only. As illustrated in Figure 1, in case 
of a fault at the shown location, Relay 3 (R3) needs to take into account not only the fault current incoming from the grid connection but also the contributions of the local DGs, DG1 and DG2.

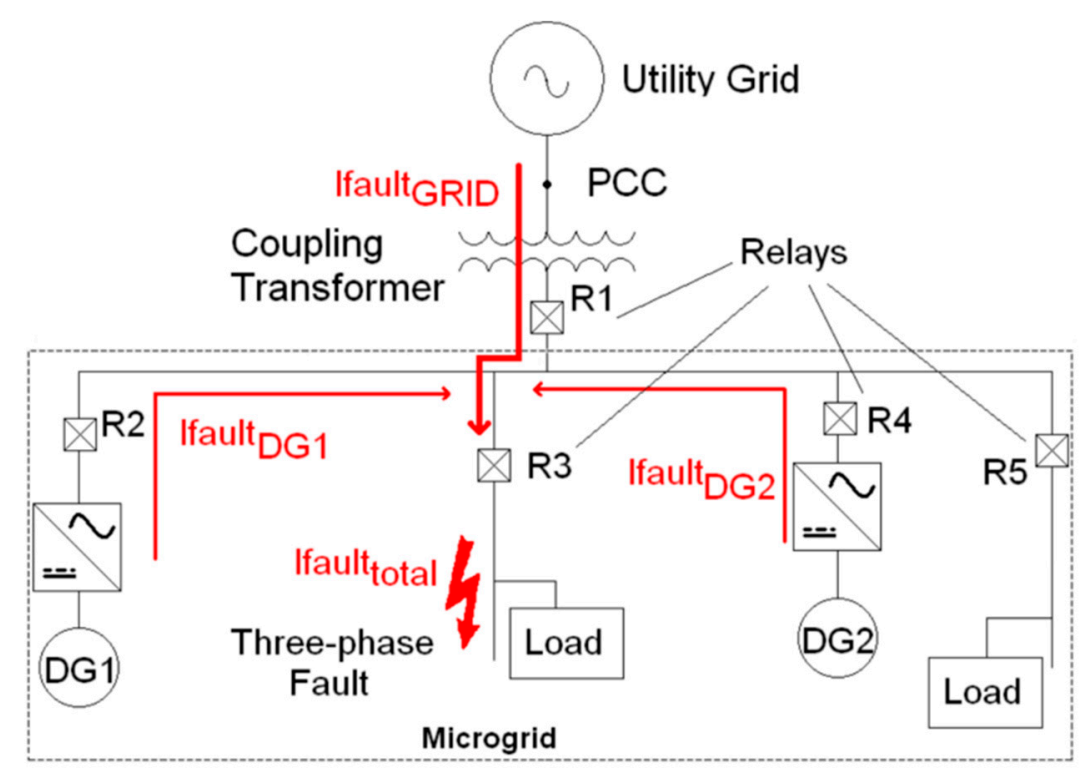

Figure 1. Protection issues with inverter interfaced DGs.

Using the summation of all fault current contributions may seem a convenient and simple solution. However, the issue is more complex. DGs may stop generation at any time due to a myriad of reasons, e.g., due to intermittent renewable source or increase its generation output and, hence, the fault current contribution, in case of a fault. Furthermore, the distribution network may disconnect from the utility grid and continue its islanded operation. Any fault under these circumstances will experience much smaller fault current, yet it needs to be properly identified and isolated.

The accurate identification of fault contribution is crucial to proper operation of protection systems. Considering the case in Figure 2, Relay 2 (R2) experiences a large amount of fault current flowing through it. However, the proper implementation of selectivity requires that Relay 8 (R8) picks up and isolates the fault not Relay 2 . There are several communication-based protection solutions proposed in the literature to counter these problems $[25,26]$. However, for proper operation of such systems, thorough understanding of inverter's fault behavior is key. Only in that fashion is it possible to anticipate different fault conditions and program protection devices.

In addition to these challenges, SIs are highly dynamic devices that interact with the grid and try to influence its operation. They are able to operate in a series of modes which change SI's output with respect to local voltage and/or frequency. This makes them more unpredictable. Therefore, there is an imminent need to investigate fault behavior of SIs. Using PHIL tests increases the fidelity of the results as explained in the next section. 


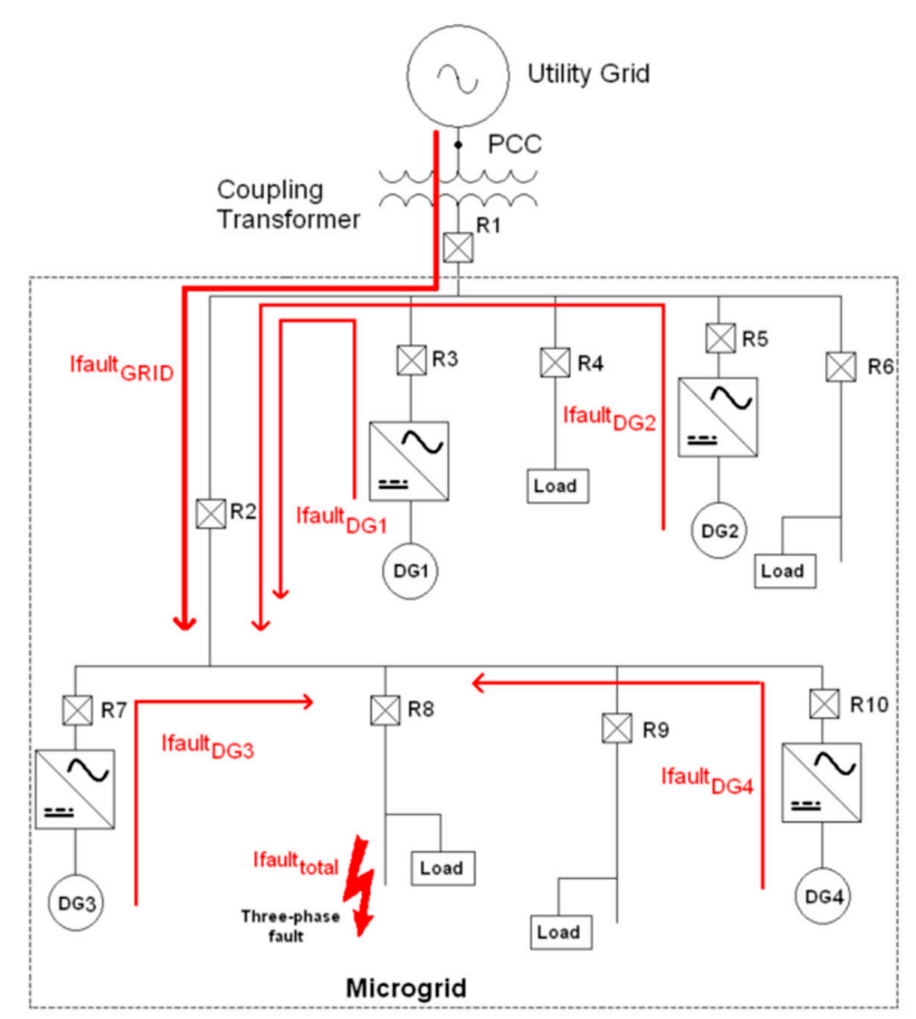

Figure 2. Selectivity problem with embedded generation.

\section{PHIL Test Set Up and Smart Inverter Integration}

In order to study the fault behavior of SIs, a Power Hardware-in-the-loop (PHIL) test setup has been prepared as shown in Figure 3 below. This figure illustrates the power and communication lines between the equipment involved in testing. The equipment list is given in Table 1. At the heart of the setup is Device Under Test (DUT), which is a $5.5 \mathrm{~kW}$ residential smart inverter. It is fed by a PV simulator that is rated $300 \mathrm{kVA}$. The output of DUT is fed to a grid simulator, which is a power amplifier rated $30 \mathrm{kVA}$ by Ametek. This grid simulator acts as the power exchange interface between DUT and Digital Real-Time Simulator (DRTS). Details of the simulation model developed inside DRTS are given further below.

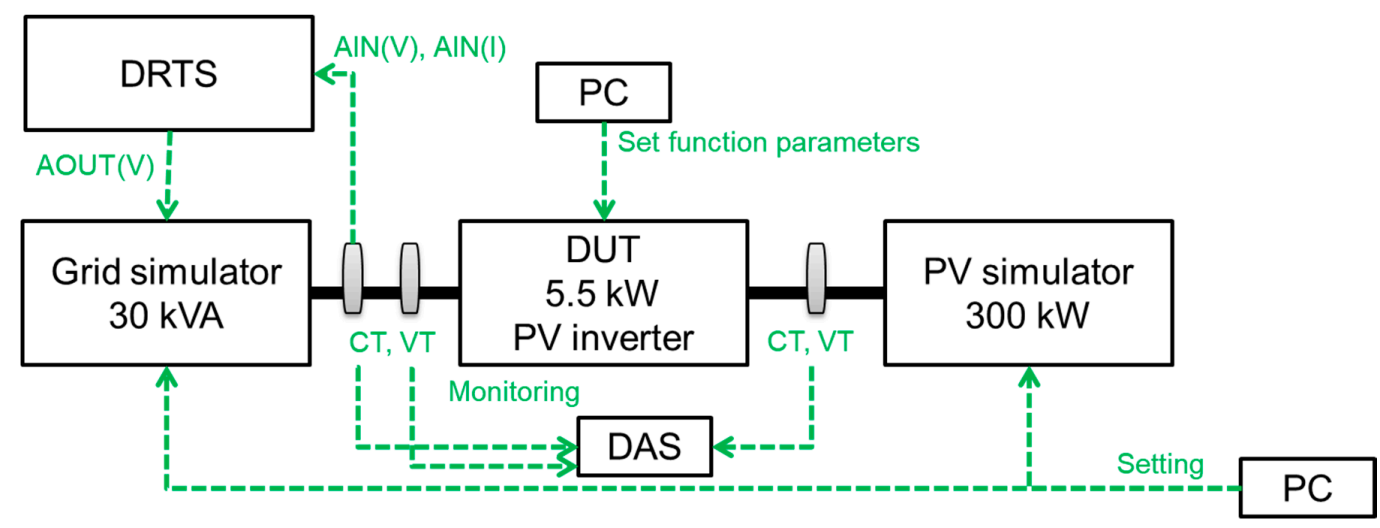

Figure 3. PHIL Test Setup with communication and control connections. 
Table 1. PHIL Test Equipment List.

\begin{tabular}{ccc}
\hline Equipment & Manufacturer-Model & Rating \\
\hline DUT & Tabuchi SI-THD-S55P3B-US & $5.5 \mathrm{~kW}$ \\
Grid Simulator & Ametek-MX30 & $30 \mathrm{kVA}$ \\
PV simulator & SanRex & $300 \mathrm{kVA}$ \\
DAS & Power meter: Yokogawa WT3004E & - \\
DRTS & Power quality analyzer: HIOKI PW3198 & - \\
\hline
\end{tabular}

A Data Acquisition System (DAS) is utilized to collect test and monitoring data. It consists of two components: a power meter and a power quality analyzer. Current and voltage values as well as frequency data are collected. Two separate personal computers are utilized to configure DUT and both simulators (Grid and PV). The electrical connections are denoted by hard black lines while communication lines are shown as green hashed lines. It is especially worthy to note that DRTS is fed the current and voltage values of the DUT's terminals. These values are utilized to incorporate DUT into real-time simulation studies.

Figure 4 shows the detailed wiring of the PHIL test setup. Grid amplifier is fed by 200 V, 200 A grid connection and communicated with DRTS to reflect simulation conditions to DUT. DUT is a single-phase residential SI rated at $5.5 \mathrm{~kW}$. It has a separate controller panel and $9.89 \mathrm{kWh}$ rated storage system. SI's solar input is provided by the PV simulator, which is fed by $420 \mathrm{~V}, 750 \mathrm{kVA}$ source.

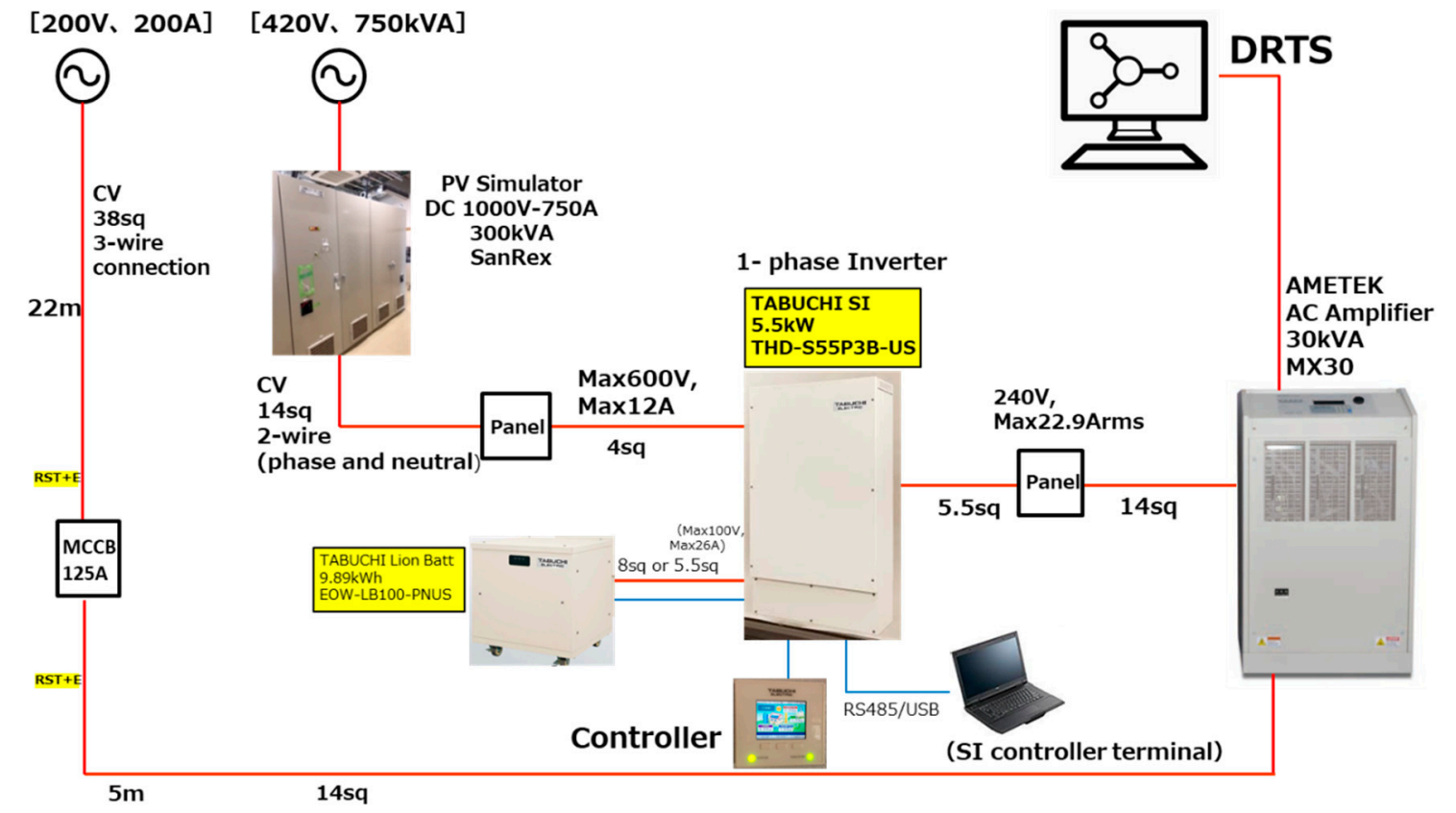

Figure 4. Lab Test Connections.

The interface between the real-life and DRTS simulation is an intricate process where the sampled values, their scales and what they represent need to be carefully engineered. As shown in Figure 5, the SI terminal voltages are sampled by Current Transformer (CT) and Voltage Transformer (VT) with 1:3000 and 10:500 windings, respectively. These analog values of phase $A$ voltage $\left(V_{a}\right)$ and phase $A$ current $\left(\mathrm{I}_{\mathrm{a}}\right)$ are supplied to DRTS's analog input card (GTAI). DUT is a single-phase residential SI and these parameters are sufficient to represent it inside the simulation. When the simulation is run and next time step value for the grid is obtained. DRTS outputs these values through its analog output card (GTAO), i.e., all three phase voltages, to grid simulator. In this fashion, the real-life behavior of SI 
is reflected within the simulation models and grid dynamics are applied to SI through grid simulator which receives its operating conditions from the simulation outputs.

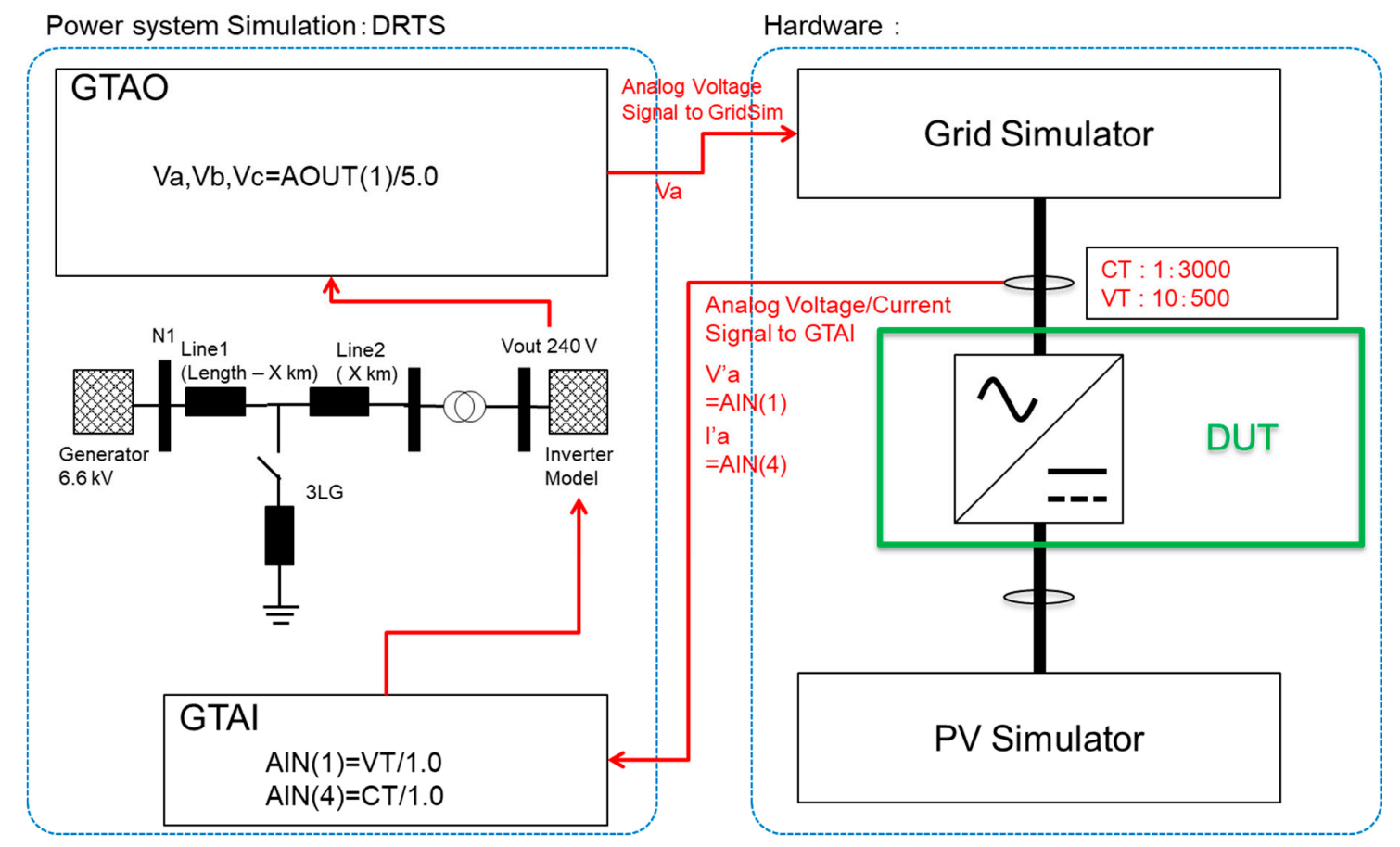

Figure 5. Simulation and Hardware Integration for Fault Behavior Studies.

The design of the simulated system is very crucial to getting desired results. It is equivalent to asking the correct questions to DUT to get correct answers. To that end, the system shown in Figure 6 is modeled. The large source on the left-most end represents the utility grid. The SI is connected to the right-most part of the system. A fault is placed in between at X distance from the DUT. This allows for sweeping studies where the value of $X$ can be swept from 0 to $100 \%$. In other words, this would place the fault at the terminals of the inverter to the point of common coupling with the utility grid. Since the focus of this study is to study and document SI's fault behavior, this approach is very beneficial. It not only shows SI's fault behavior for faults nearby but also that are very far, which occurs somewhere down in the grid. By sweeping the $\mathrm{X}$ value, it is also possible to investigate whether there are critical points where the impact of a fault diminishes due to its relative location to DUT. Finally, when $X$ is a small value, that places a large inductor (i.e., a power line) between the grid and the DUT. This represents a weak-grid scenario where SIs are placed far away from the point of grid connection. This case is especially worthy of investigation as the phenomenon of momentary cessation may occur under these circumstances.

The transformer, shown within green hashed lines, was not initially included in the system model. Originally, the system was simulated at $210 \mathrm{~V}$ throughout. However, this resulted in an unexpected stability issue as shown in Figure 7. The SI terminal voltages as well as the load voltages go out of bounds. These voltages are captured within DRTS simulations when there is no fault. Real data measurements taken at the terminals of DUT in the lab, however, showed stable voltage values. The reason for this issue is the shortcoming of RSCAD modeling software used by DRTS. Due to well-documented limitations of this software [27], detailed inverter models cannot be used for simulations with grid connections. Therefore, a simplified version, PQ source, is utilized to represent the same device. In this solution, only equivalent $P$ and $Q$ values are injected while voltage and current values are expected to settle down on a value. While this approach may work for certain scenarios, for low-voltage systems the values simply do not stabilize at a value. This had to be solved. 


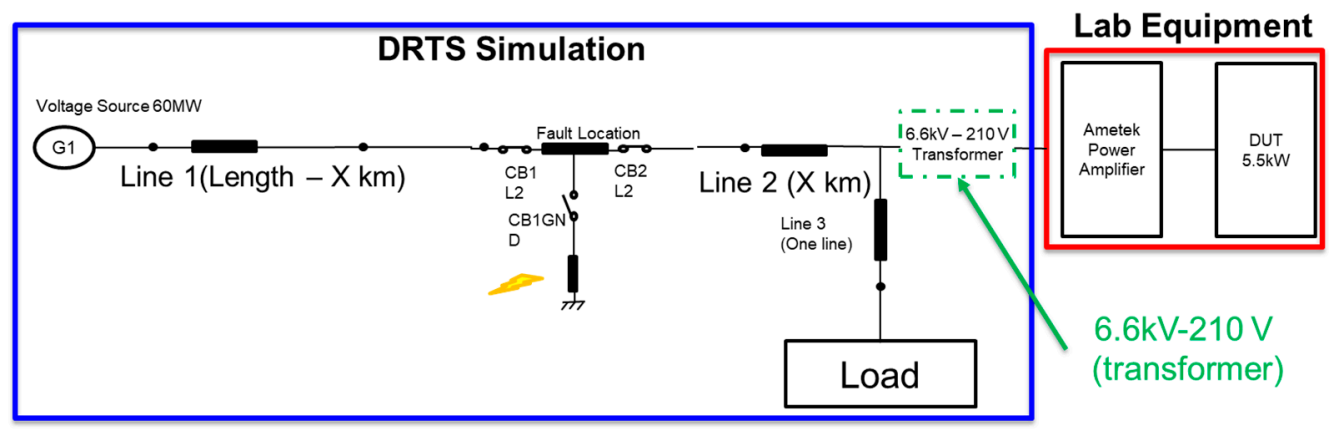

Figure 6. Simulated System in DRTS.

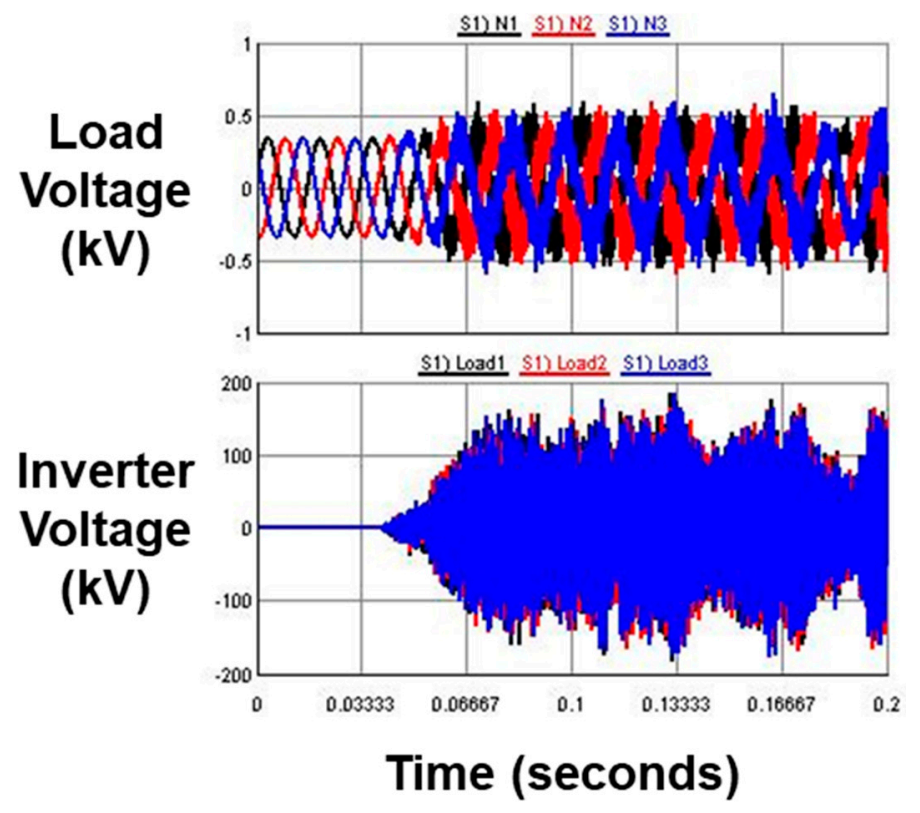

Figure 7. Inverter model becoming unstable at $210 \mathrm{~V}$ level (No fault triggered).

The first solution approach utilized was increasing the voltage levels in simulation works. This was selected based on two observations. Firstly, no matter what the simulated voltage is, DUT is physically connected to $210 \mathrm{~V}$ and sees a fault under these conditions. Secondly, with these voltages, the inverter model utilized in DRTS is stable and simulations can proceed smoothly. The most important concern, however, was keeping the interventions to a minimum. As will be discussed next, introduction of a transformer changes the topology and transformer windings do impact the simulation results. The simulations were run at several voltage values, namely: $230 \mathrm{kV}, 6.6 \mathrm{kV}, 3 \mathrm{kV}$, and $2 \mathrm{kV}$. Lower voltages were also tried but $2 \mathrm{kV}$ seems to be the threshold for stability in this case. The results and their interpretations are given in the next section.

The problem with the above solution is that there is no consistent voltage value. DUT and lab equipment, including the grid simulator, operate at $210 \mathrm{~V}$ while the simulation studies assume a much higher value. Although the results are consistent and show a clear fault behavior pattern, this was a concern. Therefore, a second solution approach was assumed where a transformer is inserted at the terminals of simulated SI's terminals, as shown in Figure 6. In other words, the transformer is only added inside DRTS, not in the lab. The benefit of this approach is that consistent voltage values are utilized, and they are not arbitrarily changed in DRTS-lab interface. On the other hand, placing a transformer effectively adds large inductors between the grid and DUT. This impacts the current waveforms and fault behavior. It is true, however, that in real-life, residential SIs are connected to 
distribution network via pole-transformers [28]. Therefore, despite altering the fault behavior of a single SI, the addition of a transformer gives more realistic results that may be encountered in real distribution networks.

The test results of both these cases and their analyses are given in the next section.

\section{Fault Behavior Test Results}

Different fault tests have been performed with the test configuration that is explained in the preceding section. Due to the above-mentioned stability issues, two different simulation models were utilized during the test. For either model, the fault location is swept from $0 \%$ to $100 \%$ in $20 \%$ increments. This effectively investigates the impact of fault location relative to DUT.

\subsection{Test Results with Different Voltage Approach}

Simulations are performed with a range of voltage levels. The observed behavior is exactly the same, provided that the voltage is high enough for simulation models to converge. For this reason, here the results of only the $6.6 \mathrm{kV}$ tests are shown. This also makes it easier to compare the results with the transformer-based approach where the distribution network voltage is also $6.6 \mathrm{kV}$.

The inverter output is set as $\mathrm{P}=2.5 \mathrm{~kW}$ and $\mathrm{Q}=0$ VARs. The fault location is swept as $100 \%, 80 \%$, $60 \%, 40 \%, 20 \%$, and $0 \%$ on the far side of the line. In other words, it is gradually moved towards the DUT. As expected, when the fault is very near, DUT's output immediately becomes zero and it turns off as shown in Figure 8 (20\% and $0 \%$ cases). The spikes after the fault are cleared are due to control signals in the simulation. In reality, DUT does not reconnect and there is no P exchange after the fault.

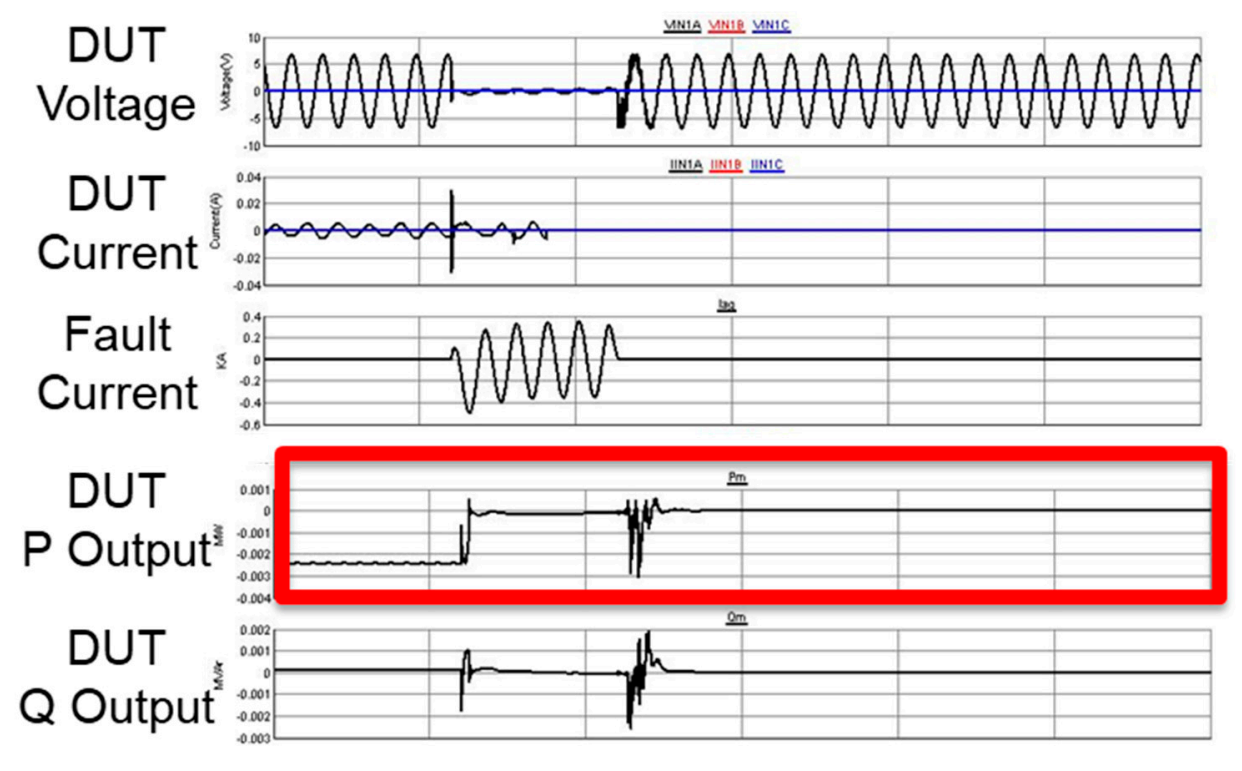

Figure 8. Test Results for $6.6 \mathrm{kV}$ simulation when $\mathrm{x}=20 \%$.

For the cases where $\mathrm{x}$ is equal to $60 \%$ and $40 \%$, momentary cessation is observed. As shown in Figure 9, DUT's P output drops to zero but recovers after the fault is cleared. Knowing when this phenomenon occurs is vital for network operators. That is because, during a fault, the system is under stress and starts to collapse. If the generators stay connected and support the grid, this particular fault may be cleared successfully. If, on the other hand, generators such as SIs stop injecting power to the grid, as it happens in this case, this will add fuel to the fire and create a downward spiral that may lead to a black-out. 


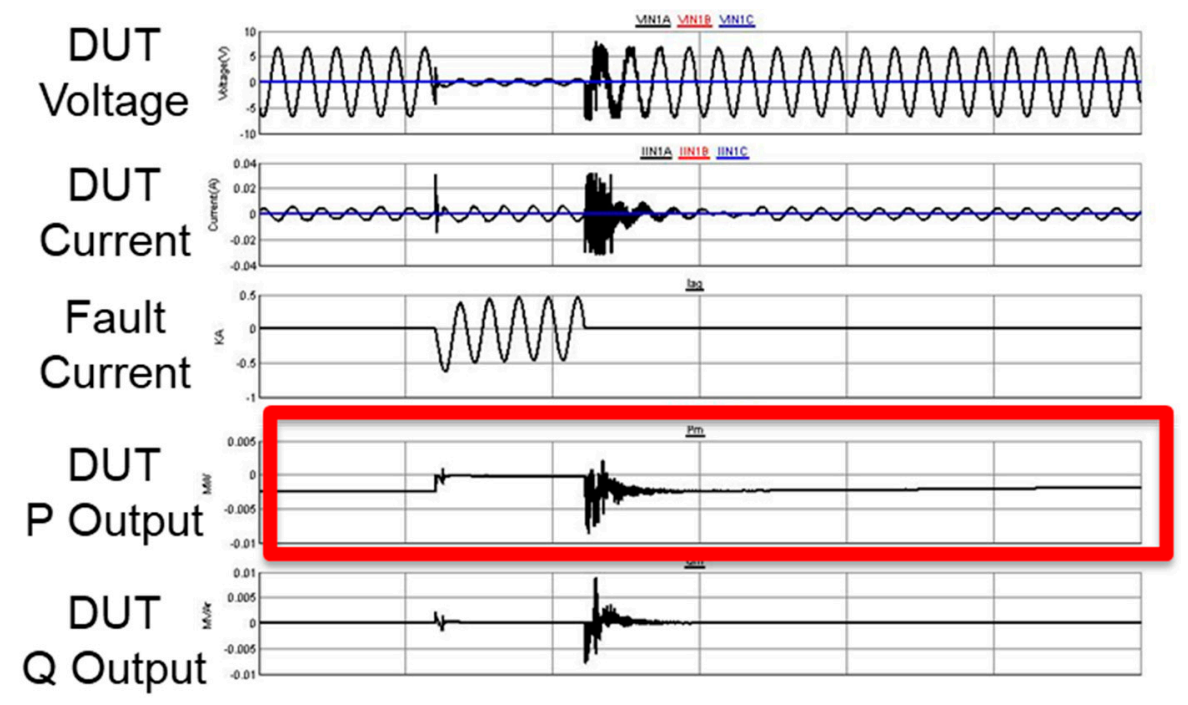

Figure 9. Test Results for $6.6 \mathrm{kV}$ simulation when $\mathrm{x}=60 \%$.

As shown in Figure 10, an interesting case occurs when the fault is far away. Due to sagging voltage, injected P reduces from $2.5 \mathrm{~kW}$ to $1.2 \mathrm{~kW}$ during the fault. Once the fault is cleared, it recovers back to its original value of $2.5 \mathrm{~kW}$ again. This mainly occurs for $100 \%$ and $80 \%$ cases, although the drop is different for both cases (when the fault is away from inverter).

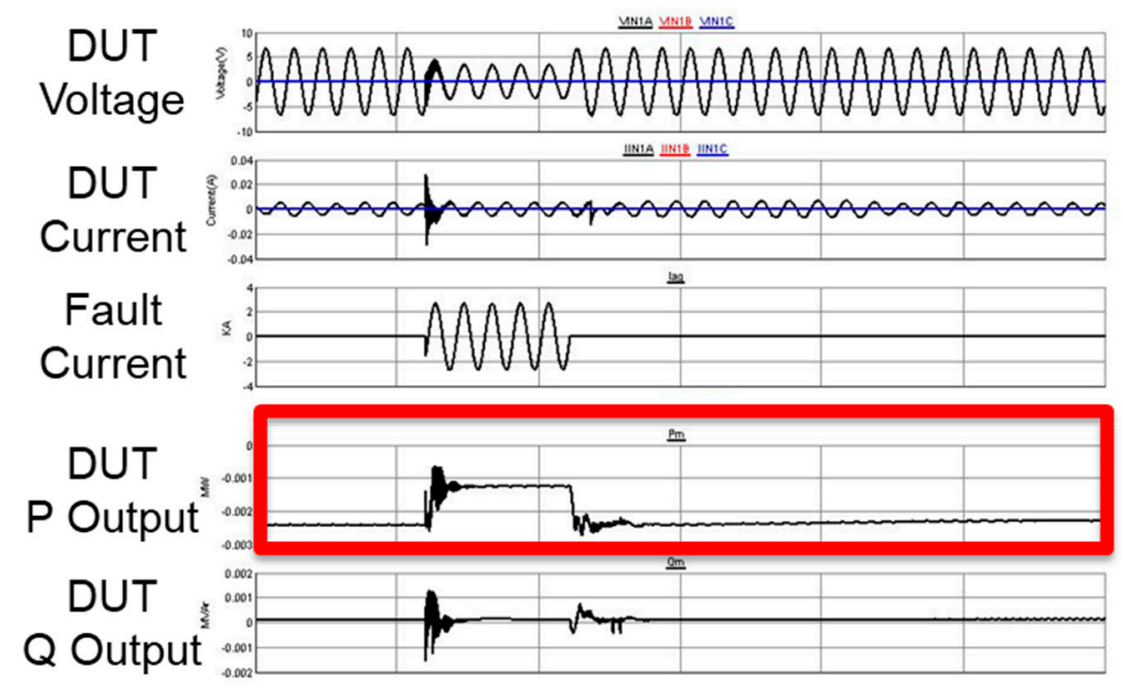

Figure 10. Test Results for $6.6 \mathrm{kV}$ simulation when $\mathrm{x}=100 \%$.

Results obtained with other voltage levels are very similar and shows the same trend with some interesting observations. For instance, a case may seem stable at a certain voltage level and may go out of bounds when a fault is triggered. As shown in Figure 11, at $3 \mathrm{kV}$, the simulation model is stable before the fault is triggered but it never settles down after the fault is cleared. $P, Q$, and voltage waveforms of DUT clearly show this as well. These findings created some questions about the results obtained in this fashion. Three main concerns about them are as follows:

(1) Simulations do not use $210 \mathrm{~V}$ (415 L-L). The voltage levels are arbitrarily increased to achieve stability. While this solves stability issues, it is not scientifically justified.

(2) The line connection between the grid and the DUT in simulations is expressed in per units. This means different voltage levels would yield different impedances in between. It is true that 
nearby faults turn off SIs, far away faults cause a decrease in $\mathrm{P}$ output and values in between cause a momentary cessation. While this general trend is documented for SI fault behavior, it is not possible to determine absolute values as to when SI will turn off or enter momentary cessation. For network-specific studies, this is important.

(3) There are some unwanted transients and spikes in the simulations. These seem to occur after transients, e.g., fault occurrence and fault clearance. Therefore, obtained simulation results show how the $\mathrm{P}$ output of Tabuchi changes before, during, and after a fault, e.g., $2.5 \mathrm{~kW}$ during a fault drops to $1.2 \mathrm{~kW}$ during the fault and recovers to $2.5 \mathrm{~kW}$. If the main concern is to see how much $P$ will be lost from SIs during a fault and relate this to distance of the fault, these results may be sufficient. If the exact transient behavior is of interest, then these results do not give the full picture.

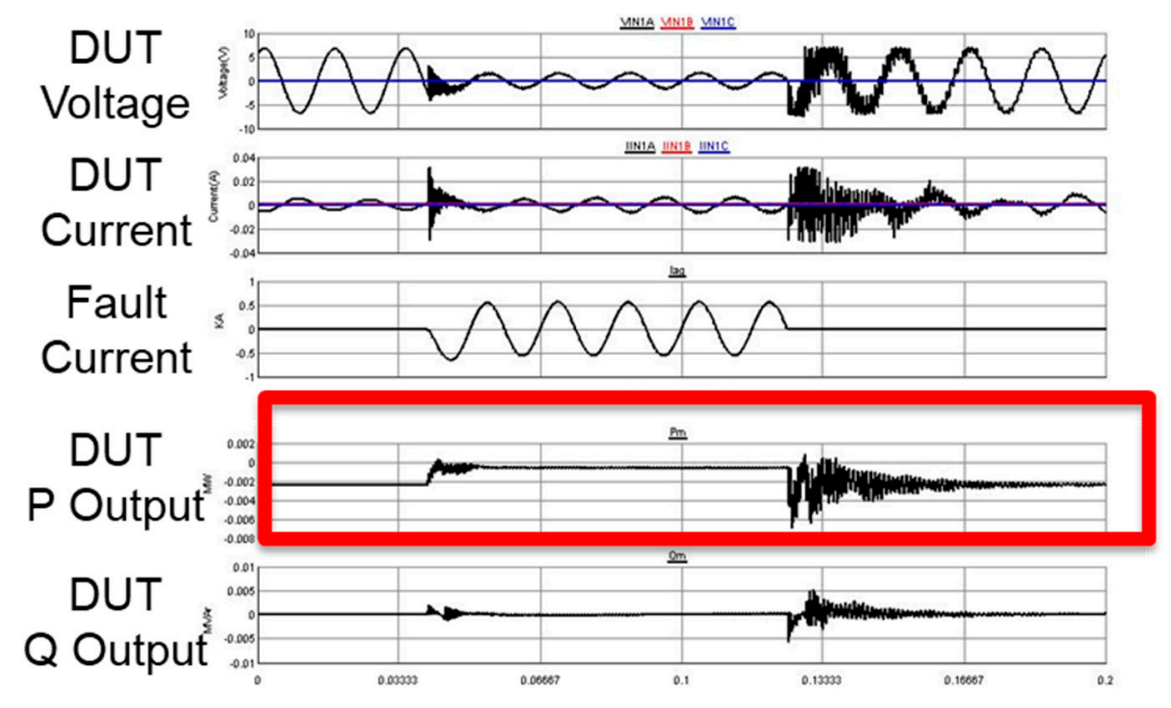

Figure 11. Test Results for $3 \mathrm{kV}$ simulation when $\mathrm{x}=20 \%$.

Considering these concerns, the simulated model has been revised and a pole-transformer, which is widely used in distribution networks, is inserted between DUT and the rest of the system.

\subsection{Test Results with Additional Transformer}

The addition of a pole transformer in front of the DUT also tackles DRTS's stability issues and is deemed a better solution. There are several reasons for this conclusion. First of all, this is in-line with on-site implementations. Residential SIs are always connected to the network via distribution transformers. Secondly, this is a scientifically sound solution as it is duplicable and well justified. It can be argued that the additional impedance values brought by the transformer windings will alter the results. In other words, plain fault behavior of an SI cannot be observed. While this is true, the focus of this research is investigating fault behavior of SIs when they are operating in distribution networks. Absolute stand-alone operation of SIs is not possible and fault behavior is not of any concern.

The impact was clear in the test results. As shown in Figure 12, DUT turned off immediately in case of a fault. No momentary cessation of drop-recovery phenomena is observed. This was valid for all cases except $x=100 \%$. There are more ripples during transients, especially in current waveforms. This is due to current flowing through transformer inductors. Only in the last case where the fault location is far, i.e., $x=100 \%$, a drop and recovery in P output is observed. As shown in Figure 13, the results indicate that the P output of DUT drops from $2.5 \mathrm{~kW}$ to $1.2 \mathrm{~kW}$ before recovering back to its original value. This is identical to results obtained without transformers. It shows that although the 
addition of transformer affects voltage and current waveforms (more ripples), it does not affect fault behavior of DUT, if it is on.

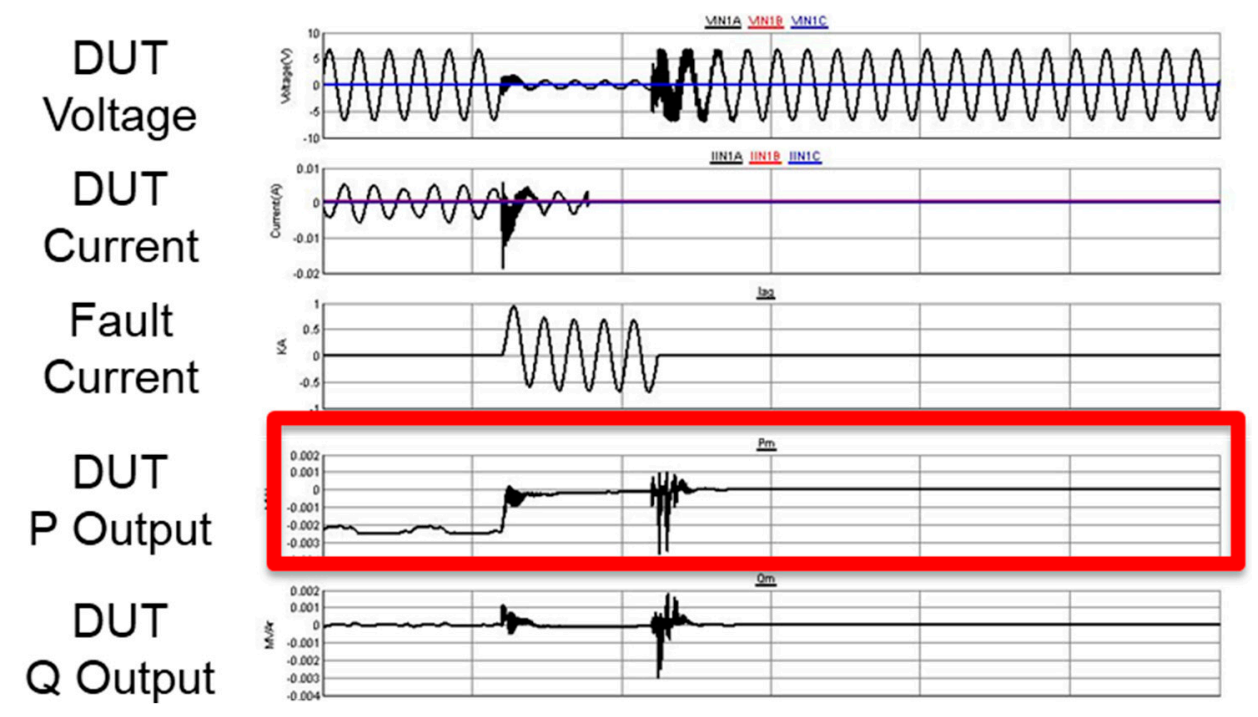

Figure 12. Test Results for $6.6 \mathrm{kV}: 210 \mathrm{~V}$ simulation when $\mathrm{x}=60 \%$.

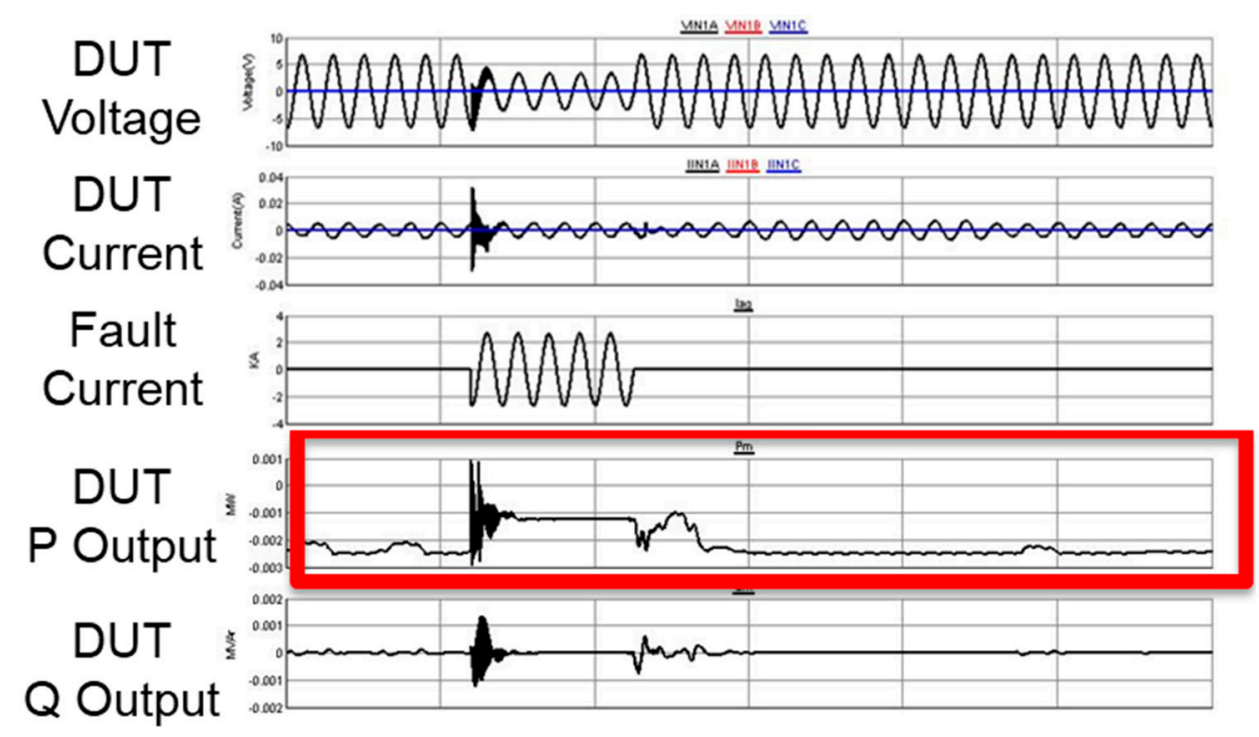

Figure 13. Test Results for $6.6 \mathrm{kV}: 210 \mathrm{~V}$ simulation when $\mathrm{x}=100 \%$.

When the results obtained in both cases are compared, it is concluded that SIs with transformer connection tends to trip and disconnect from the network more. Momentary cessation of generation is not encountered with transformer connection. It may occur between the last two cases, i.e., when $80 \%<X<100 \%$. Regardless, connection of SIs to the system with transformers decreases its probability.

These studies show that RSCAD models are not sufficient to perform PHIL fault studies at distribution level where voltages are low, and currents are high. The two solution approaches for simulation stability yielded very similar results and printed a clear trend. However, absolute fault locations of where different phenomena, e.g., momentary cessation, may occur is hard to define. Of the two solution approaches, the latter is close to real-life implementations, although it affects the output waveforms due to transformer windings. 
If the main focus is to determine how much $\mathrm{P}$ drop is caused by a fault and relate this to the fault location, the obtained results are sufficient. This piece of information can be used by grid operators to estimate how much real power $\mathrm{P}$ will be lost in case of a certain fault. If a detailed transient behavior is desired to be documented, then current PHIL capabilities is not sufficient to perform such studies.

\subsection{Test Results When Volt-Var Mode Is Active}

In order to investigate the impact of Volt-Var mode on fault behavior, a set of tests have been performed. It is documented that such SI capabilities impact operation of distribution networks in terms of voltage, current, real, and reactive power flows [28]. However, fault conditions are extreme transients and the impact of operating modes might be less significant. As Figure 14 below shows, Volt-Var mode does not impact the fault behavior substantially. The only difference is that at $60 \%$ fault case, SI does not trip off when the Volt-Var function is activated. This can be explained by the fact that in this mode SI supports the sagging voltage and opposes its decrease. This helps SI stay connected to the network. For faults closer to SI, e.g., $x=40 \%$, the voltage sag is very strong and Volt-Var mode cannot help lifting it.

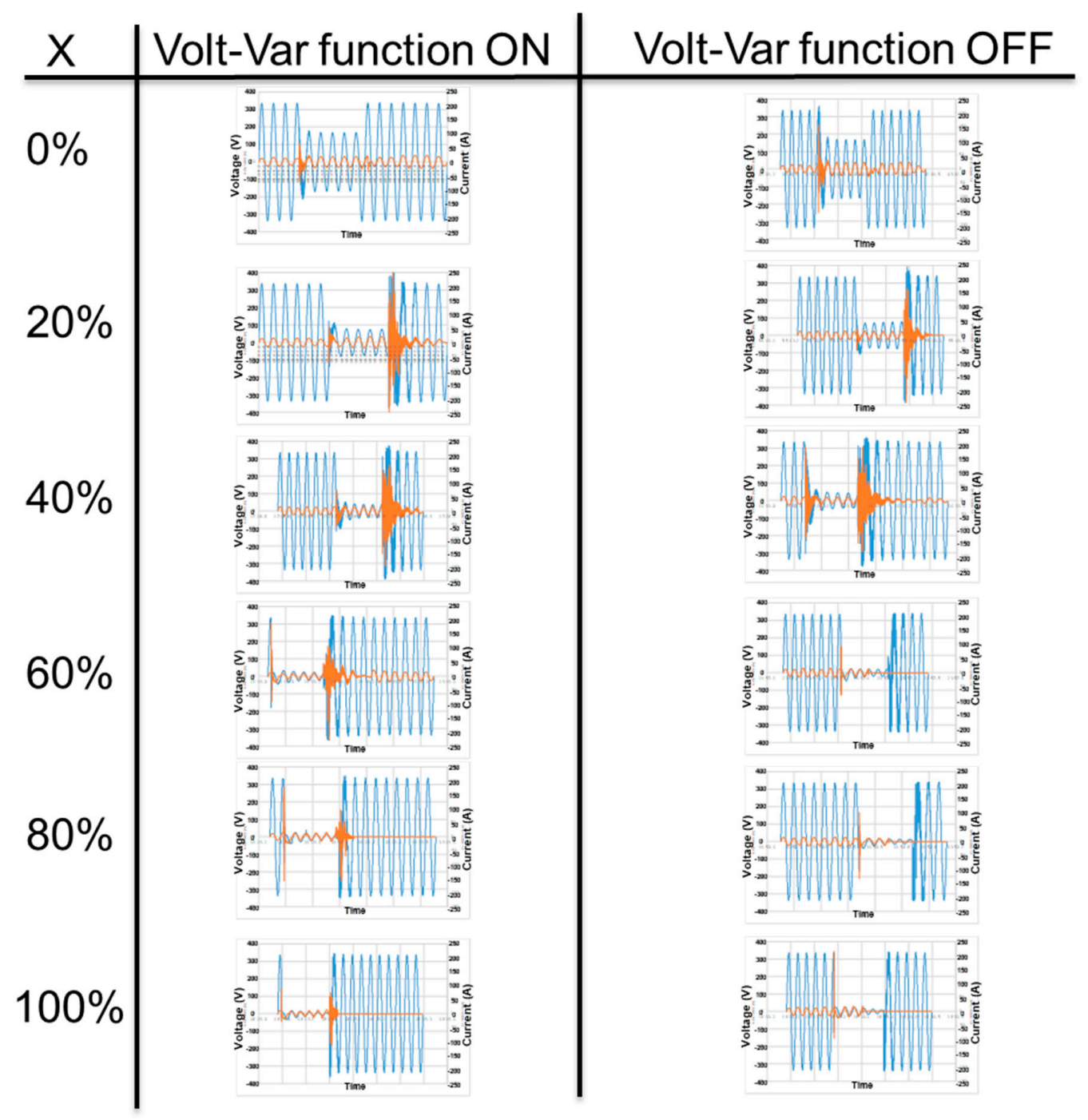

Figure 14. Test Results for 6.6 kV:210 V simulations, Volt-Var Mode ON and OFF.

These results show that Volt-Var mode helps SIs stay connected to the grid longer since it helps counter the voltage dip due to a fault. This is only true for cases where the SI is strong enough to help 
support the local voltage. For other cases, Volt-Var mode being active does not make any difference. The voltage and current waveforms for SI are identical.

\subsection{Analysis of SI Disconnection}

After completing the above analyses, it became clear that there is a certain zone where momentary cessation occurs. On either side of this zone are the immediate trip and continuous operation regions. It is found out that different parameters such as line impedance and advanced capabilities of SIs impact where this zone is located.

One question that arose as a result of these analyses is the reason for SI's disconnection from the grid. SI's connection to the grid is determined by two parameters, system voltage and frequency. The performed tests showed that the voltage drop is affected by the fault's location as shown in Figure 15. It is observed that this drop is very steep when the fault is distant, i.e., the $X$ value is small. It looked like this voltage drop had an important role in determining whether an SI stays connected to the grid in case of a fault.

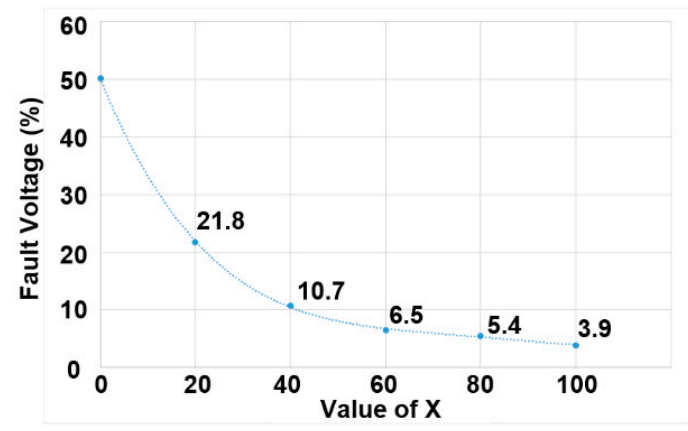

Figure 15. Fault Voltage (\% of nominal voltage) vs. Fault location.

However, further investigation showed the opposite. Table 2 shows Voltage Ride Through (VRT) rules that are implemented in DUT. It can be observed that VRT settings stipulate very long trip times. For instance, in the UV3 operating region, which corresponds to almost all fault tests (X $=20,40,60,80$, and 100), SI is required to trip due to low voltage after $2 \mathrm{~s}$. The default fault duration used in PHIL tests reported above is $0.0833 \mathrm{~s}$ and a trip due to LVRT is very unlikely.

Table 2. Voltage Ride Through (L\&H-VRT) Settings DUT [29,30].

\begin{tabular}{ccccccc}
\hline $\begin{array}{c}\text { Operating } \\
\text { Region }\end{array}$ & $\begin{array}{c}\text { Voltage at Point } \\
\text { of Interconnection } \\
\text { (\% of Nominal } \\
\text { Voltage) }\end{array}$ & $\begin{array}{c}\text { Operating } \\
\text { Mode }\end{array}$ & $\begin{array}{c}\text { Ride-Through } \\
\text { Until (s) }\end{array}$ & $\begin{array}{c}\text { Default } \\
\text { Maximum } \\
\text { Trip Time (s) }\end{array}$ & $\begin{array}{c}\text { Range of } \\
\text { Adjustability } \\
\text { Voltage Trip } \\
\text { Magnitude (\% of } \\
\text { Nominal Voltage) }\end{array}$ & $\begin{array}{c}\text { Range of } \\
\text { Adjustability } \\
\text { Clearing } \\
\text { Time (s) }\end{array}$ \\
\hline OV2 & $\mathrm{V}>120$ & $\begin{array}{c}\text { Cease to } \\
\text { Energize }\end{array}$ & N/A & 0.16 & N/A & N/A \\
\hline OV1 & $120 \geq \mathrm{V}>110$ & $\begin{array}{c}\text { Mandatory } \\
\text { Operation }\end{array}$ & 0.92 & 1 & $110-120$ & $1-13$ \\
\hline $\mathrm{CO}$ & $110 \geq \mathrm{V}>100$ & $\begin{array}{c}\text { Continuous } \\
\text { Operation } \\
\text { (Volt-Watt) }\end{array}$ & N/A & N/A & N/A & N/A \\
\hline $\mathrm{CO}$ & $100>\mathrm{V} \geq 88$ & $\begin{array}{c}\text { Continuous } \\
\text { Operation }\end{array}$ & N/A & N/A & N/A & N/A \\
\hline $\mathrm{UV} 1$ & $88>\mathrm{V} \geq 70$ & $\begin{array}{c}\text { Mandatory } \\
\text { Operation }\end{array}$ & 20 & 21 & $50-88$ & $21-50$ \\
\hline $\mathrm{UV} 2$ & $70>\mathrm{V} \geq 50$ & $\begin{array}{c}\text { Mandatory } \\
\text { Operation }\end{array}$ & $10-20$ & $11-21$ & $50-88$ & $11-50$ \\
\hline $\mathrm{UV} 3$ & $50>\mathrm{V}$ & $\begin{array}{c}\text { Momentary } \\
\text { Cessation }\end{array}$ & N/A & 2 & N/A & $0.5-21$ \\
\hline
\end{tabular}


Extra LVRT tests have been performed to assess this situation. Using the same PHIL test setup, SI terminal voltages were decreased to $4 \%$ without initiating a fault. This can be done thanks to the grid simulator's ability to control the terminal voltage of DUT. The selected voltage level corresponds to voltage levels observed when there is a fault at the terminals of DUT (i.e., $X=100$ ). The low-voltage window was repeated for four different durations, which are $0.0833 \mathrm{~s}, 0.2 \mathrm{~s}, 1 \mathrm{~s}$, and $2 \mathrm{~s}$. The results are reported in Figure 16, below. It can be clearly observed that DUT successfully rides through low-voltage values for all cases except the last one, which is the threshold identified in Table 2. This shows that the SI's tripping is not caused by voltage levels observed during faults.
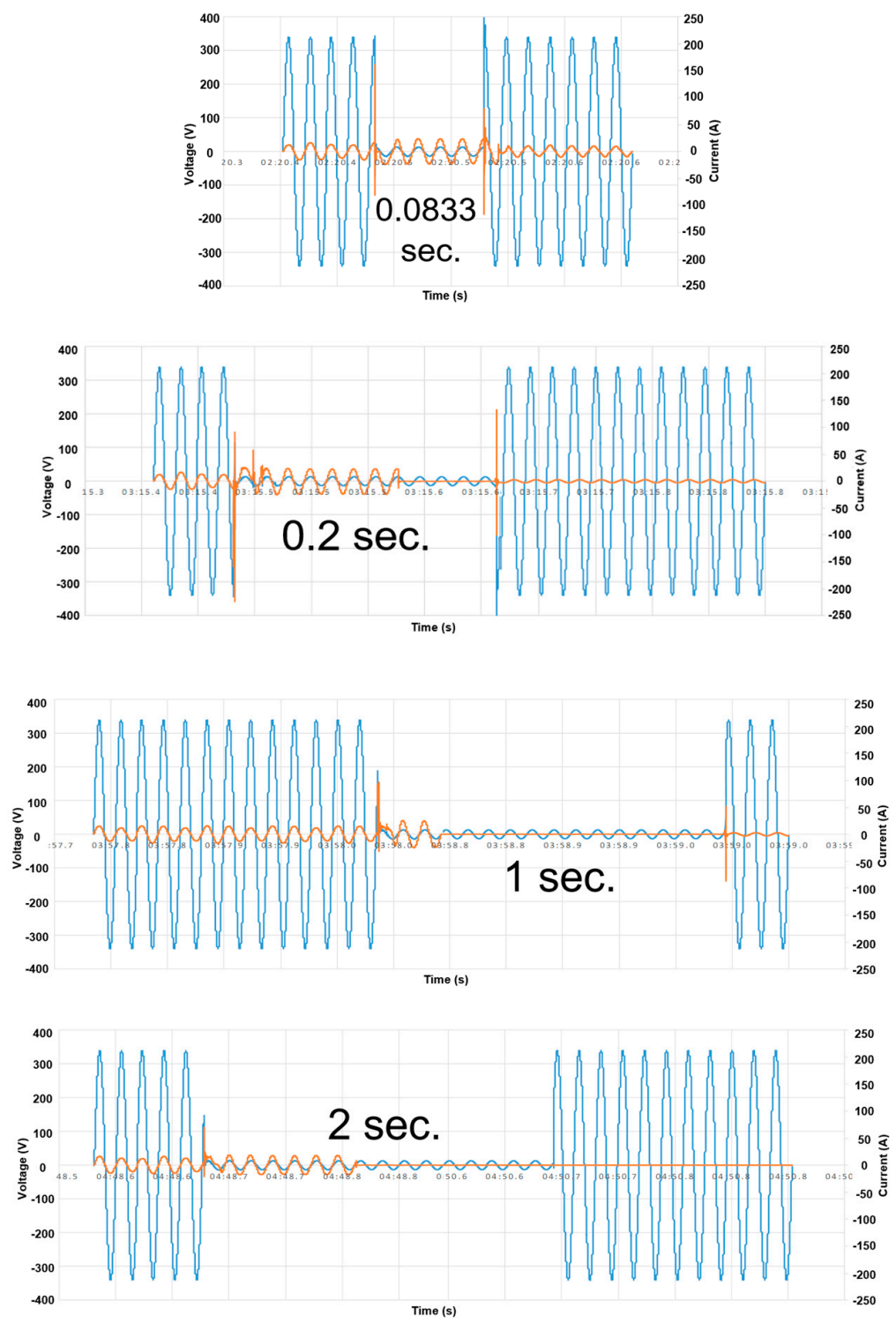

Figure 16. PHIL test results for LVRT behavior of DUT.

In order to investigate this further, a frequency plot has been added to PHIL test measurements. This helped visualize and contrast the change of frequency with different fault conditions. As shown in Figure 17, there is a direct correlation between the fault location and the magnitude of the observed frequency change. It is also important to note that this is not proportional to the voltage dip or current increase under fault conditions. This is pivotal in explaining why two similar cases, e.g., $X=40$ and $X=50$, may have different outcomes where the inverter stays connected in the former and disconnects in the latter. 


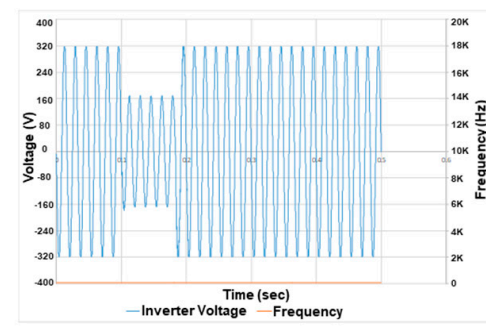

$100 \%$

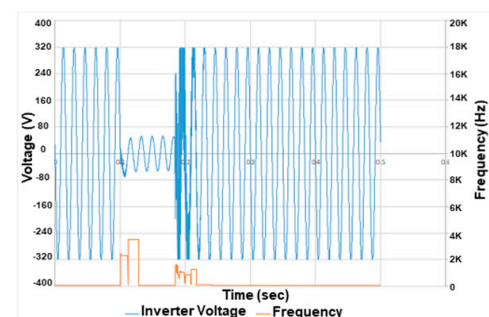

$60 \%$

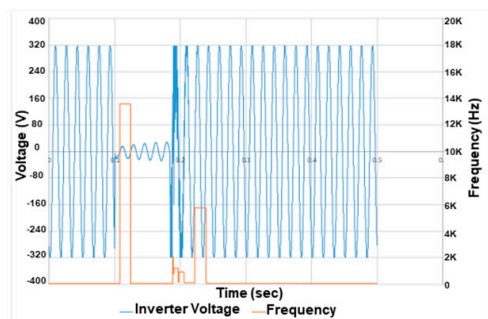

$0 \%$

Far

Near

\section{Distance of the fault from inverter}

Figure 17. Impact of fault location on system frequency.

Three test results are shown in Figure 17 where the location of the fault is moved from point of common coupling to a roughly mid-point on the line and, finally, at the terminals of the SI. The y-axis on the right corresponds to frequency and has very high scale. When the fault is far away, the fault causes a voltage sag, but the frequency stays constant at $60 \mathrm{~Hz}$ (slightly above 0 ). When the fault is moved to $X=40 \%$, there is a significant frequency disturbance during the fault which represents a spike from $60 \mathrm{~Hz}$ to almost $4 \mathrm{kHz}$. When the fault is located on the SI's terminals, this frequency spike reaches almost $14 \mathrm{kHz}$.

In addition to these extreme cases, there are cases where the fault located sufficiently far away may cause $6 \%$ increase in frequency, i.e., $60 \mathrm{~Hz}$ to $64 \mathrm{~Hz}$. This is the border of the frequency ride through rules implemented in DUT. As shown in Figure 18, any increase beyond this threshold requires an immediate disconnect while SI is stipulated to stay connected for anything at or below this value $[29,30]$. Therefore, depending on the system conditions when the fault occurs, same test setup may see SI stay connected or disconnect.

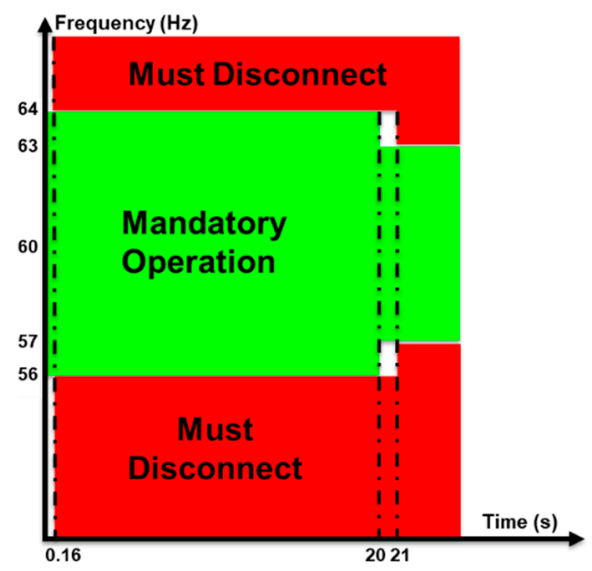

Figure 18. Frequency ride-through codes implemented in DUT.

\subsection{Analysis of SI's Current Spike}

Finally, a peculiar phenomenon was observed in every test case reported above. In case of a fault, a large amount of current spike is measured at DUT's terminals. This is contrary to the fault behavior of inverters reported in the literature [9]. Further investigation yielded that this is due to the AC filter embedded inside DUT's casing, as shown in Figure 19. When the fault causes a voltage drop, the capacitor current, $i_{c}$, reacts with a spike as the capacitor voltage, $v c$, has to be continuous. The same issue can be observed when the fault is cleared and the terminal voltages of the DUT returns 
to nominal value. The only exception is when the DUT disconnects from the grid during the fault. In that case, since there is no power injection into the grid, no current spike is observed at reconnection.

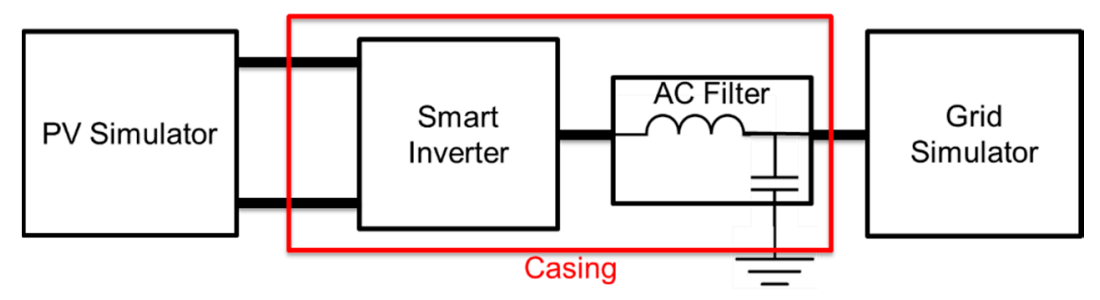

Figure 19. AC filter inside SI casing.

\section{Conclusions}

The popularity of RES-based generation gave rise to inverter-interfaced generators. Due to their sophisticated control and switching systems, these devices have a negative impact on the power system operation. One way to address these is to equip these devices with advanced capabilities. Called SIs, these devices can help with voltage and frequency control of the overall power system. However, due to their highly dynamic behavior, grid operators are reluctant to include them in their networks. Extensive behavior and impact studies are required to investigate behavior of SIs under different conditions. Fault behavior is a very important subject as it helps grid operators understand what they should expect in case of a fault. Understanding SI's behavior helps them plan in a more accurate fashion.

For this purpose, this work develops and presents a full PHIL testing platform to study the fault behavior of residential SIs connected to distribution networks. Detailed explanations of both hardware (lab set up) and software (DRTS simulation models) configurations are given as well as the interface between them. Limitations of PHIL testing and encountered problems are documented for the benefit of researchers working in this field. Results of extensive PHIL tests are presented and analyzed. It is documented that residential SIs are not affect by faults that occur very far away. Even if their real power output decreases during the fault, due to voltage sag, it returns to its original value once the fault is cleared. For faults that are closer to SI, it is observed that SI disconnects from the system, mostly due to frequency deviation reasons. For the same reason, SIs are more likely to disconnect from the network when faults with longer durations occur. Activation of advanced capabilities such as Volt-Var control increases the likelihood of an SI to stay connected and support the power network for longer times. It is also important to know the contents of the SI's casing as additional components such as AC filters can trigger certain fault behaviors, which would otherwise not be seen.

Future work should focus on improving PHIL software models so that SI fault studies at distribution level can be performed in a more holistic fashion.

Author Contributions: Conceptualization, methodology, validation, formal analysis, investigation, T.S.U., S.S. and M.S.; data curation, S.S. and M.S.; writing —original draft preparation, writing-review and editing, T.S.U.; supervision, T.S.U., J.H. and K.O.; funding acquisition, T.S.U., J.H. and K.O.; All authors have read and agreed to the published version of the manuscript.

Funding: This research received no external funding.

Conflicts of Interest: The authors declare no conflict of interest.

\section{References}

1. IEA. World Energy Outlook 2020; IEA: Paris, France, 2020. Available online: https://www.iea.org/reports/ world-energy-outlook-2020 (accessed on 11 November 2020).

2. Javed, K.; Ashfaq, H.; Singh, R.; Hussain, S.M.S.; Ustun, T.S. Design and Performance Analysis of a Stand-alone PV System with Hybrid Energy Storage for Rural India. Electronics 2019, 8, 952. [CrossRef] 
3. Sarwar, S.; Mokhlis, H.; Othman, M.; Muhammad, M.A.; Laghari, J.A.; Mansor, N.N.; Mohamad, H.; Pourdatyaei, A. A Mixed Integer Linear Programming Based Load Shedding Technique for Improving the Sustainability of Islanded Distribution Systems. Sustainability 2020, 12, 6234. [CrossRef]

4. Masaba, K.; Ntakirutimana, A.; Ustun, T.S. Design and implementation of a smart irrigation system for improved water-energy efficiency. In Proceedings of the 4th IET Clean Energy and Technology Conference (CEAT 2016), Kuala Lumpur, Malaysia, 14-15 November 2016; pp. 1-5.

5. Aleem, S.A.; Hussain, S.M.S.; Ustun, T.S. A Review of Strategies to Increase PV Penetration Level in Smart Grids. Energies 2020, 13, 636. [CrossRef]

6. El Mekaoui, A.; Tariq, R.; Ramírez, O.B.; Méndez-Monroy, P. Sustainability, Sociocultural Challenges, and New Power of Capitalism for Renewable Energy Megaprojects in an Indigenous Mayan Community of Mexico. Sustainability 2020, 12, 7432. [CrossRef]

7. IRENA. Global Renewables Outlook: Energy Transformation 2050; International Renewable Energy Agency: Abu Dhabi, UAE, 2020; ISBN 978-92-9260-238-3.

8. Electric Power Research Institute (EPRI). Common Functions for DER Group Management, 3rd ed.; Technical Report; EPRI: Washington, DC, USA, November 2016; p. 138.

9. Ustun, T.S. Design and Development of a Communication-Assisted Microgrid Protection System. Ph.D. Thesis, Victoria University, Melbourne, Australia, 2013.

10. Orihara, D.; Iioka, D. Sensitivity-based AGC Dispatching for Mitigation of Short-Term Power Flow Variation. In Proceedings of the 2018 IEEE Electronic Power Grid (eGrid), Charleston, SC, USA, 12-14 November 2018; pp. 1-6.

11. Howlader, A.M.; Matayoshi, H.; Sepasi, S.; Senjyu, T. Design and Line Fault Protection Scheme of a DC Microgrid Based on Battery Energy Storage System. Energies 2018, 11, 1823. [CrossRef]

12. Hariri, M.H.M.; Desa, M.K.; Masri, S.; Zainuri, M.A.A.M. Grid-Connected PV Generation SystemComponents and Challenges: A Review. Energies 2020, 13, 4279. [CrossRef]

13. Communication Networks and Systems for Power Utility Automation. Part 90-7: Object Models for Power Converters in Distributed Energy Resources (DER) Systems. Available online: https://webstore.iec.ch/ preview/info_iec61850-90-7\%7Bed1.0\%7Den.pdf (accessed on 11 November 2020).

14. Huque, A. Smart Inverter Grid Support Functions and Potential Impact on Reliability. In Proceedings of the 2015 NREL Photovoltaic Reliability Workshop, Golden, CO, USA, 25 February 2015.

15. Pilehvar, M.; Mirafzal, B. Frequency and Voltage Supports by Battery-Fed Smart Inverters in Mixed-Inertia Microgrids. Electronics 2020, 9, 1755. [CrossRef]

16. Shigenobu, R.; Nakadomari, A.; Hong, Y.-Y.; Mandal, P.; Takahashi, H.; Senjyu, T. Optimization of Voltage Unbalance Compensation by Smart Inverter. Energies 2020, 13, 4623. [CrossRef]

17. Soyoye, O.T.; Stefferud, K.C. Cybersecurity Risk Assessment for California's Smart Inverter Functions. In Proceedings of the 2019 IEEE CyberPELS (CyberPELS), Knoxville, TN, USA, 29 April-1 May 2019; pp. 1-5.

18. Ustun, T.S. Cybersecurity Vulnerabilities of Smart Inverters and Their Impacts on Power System Operation. In Proceedings of the 2019 International Conference on Power Electronics, Control and Automation (ICPECA), New Delhi, India, 16-17 November 2019; pp. 1-4.

19. Montoya, J.; Brandl, R.; Vishwanath, K.; Johnson, J.; Darbali-Zamora, R.; Summers, A.; Hashimoto, J.; Kikusato, H.; Ustun, T.S.; Ninad, N.; et al. Advanced Laboratory Testing Methods Using Real-Time Simulation and Hardware-in-the-Loop Techniques: A Survey of Smart Grid International Research Facility Network Activities. Energies 2020, 13, 3267. [CrossRef]

20. Lauss, G.; Lehfuß, F.; Bletterie, B.; Strasser, T.; Bründlinger, R. Examination of LV grid phenomena by means of PHIL testing. In Proceedings of the IECON 2012-38th Annual Conference on IEEE Industrial Electronics Society, Montreal, QC, USA, 25-28 October 2012; pp. 4771-4776.

21. Kikusato, H.; Ustun, T.S.; Suzuki, M.; Sugahara, S.; Hashimoto, J.; Otani, K.; Shirakawa, K.; Yabuki, R.; Watanabe, K.; Shimizu, T. Microgrid Controller Testing Using Power Hardware-in-the-Loop. Energies 2020, 13, 2044. [CrossRef]

22. Gururaj, M.V.; Padhy, N.P. PHIL experimentation on fault ride through behavior of doubly fed induction generator-based wind system in the presence of fault current limiter. In Proceedings of the 2018 IEEMA Engineer Infinite Conference (eTechNxT), New Delhi, India, 13-14 March 2018; pp. 1-6.

23. Media, G. Tabuchi Brings Japan's Solar-Storage Lessons to North American Markets. 2015. Available online: https://bit.ly/34rb5Th (accessed on 11 November 2020). 
24. Oudalov, A.; Fidigatti, A. Adaptive Network Protection in Microgrids. European Union CLUSTERIntegration Project 2008. Available online: www.microgrids.eu/documents/519.pdf (accessed on 11 November 2020).

25. Ustun, T.S.; Khan, R.H.; Hadbah, A.; Kalam, A. An adaptive microgrid protection scheme based on a wide-area smart grid communications network. In Proceedings of the 2013 IEEE Latin-America Conference on Communications, Santiago, Chile, 24-26 November 2013; pp. 1-5.

26. Memon, A.A.; Kauhaniemi, K. An Adaptive Protection for Radial AC Microgrid Using IEC 61850 Communication Standard: Algorithm Proposal Using Offline Simulations. Energies 2020, 13, 5316. [CrossRef]

27. Ustun, T.S.; Hashimoto, J.; Otani, K. Using RSCAD's Simplified Inverter Components to Model Smart Inverters in Power Systems. In Proceedings of the 2018 IEEE Workshop on Complexity in Engineering (COMPENG), Florence, Italy, 10-12 October 2018; pp. 1-6.

28. Ustun, T.S.; Aoto, Y. Analysis of Smart Inverter's Impact on the Distribution Network Operation. IEEE AccesS 2019, 7, 9790-9804. [CrossRef]

29. Hawaiian Electric Companies. Hawaiian Electric Companies' Grid Support Utility-Interactive Inverter Standards. 2017. Available online: https://bit.ly/3ou7Ceq (accessed on 11 November 2020).

30. UL Standard. UL 1741-Inverters, Converters, Controllers and Interconnection System Equipment for Use with Distributed Energy Resources, 2nd ed.; UL: Northbrook, IL, USA, 2010.

Publisher's Note: MDPI stays neutral with regard to jurisdictional claims in published maps and institutional affiliations.

(C) 2020 by the authors. Licensee MDPI, Basel, Switzerland. This article is an open access article distributed under the terms and conditions of the Creative Commons Attribution (CC BY) license (http://creativecommons.org/licenses/by/4.0/). 